One patient developed severe haematemesis needing inpatient therapy and had to be withdrawn from the trial. In retrospect it was clear that he should not have been admitted to the trial because he had a history of peptic ulceration.

\section{Discussion}

Controlled trials of treatment in Bell's palsy are difficult to perform because of delay in starting therapy which is likely to prejudice the result. For this reason the patients were subdivided into early and late groups. Sixty-six started treatment on the first or second day of paralysis and 120 on the third or fourth days. The results of earlier treatment were indeed better, though both groups showed benefit. However, in very severe attacks the major damage may be done within the first few hours and treatment should be started at once.

It has previously been shown that the outcome in untreated Bell's palsy becomes worse with increasing age (Langworth and Taverner, 1963) so the patients were further subdivided into young and older groups. There were 104 patients in the young group and 82 in the older group. The expected difference was observed, but in the whole series the mean age of the patients who developed denervation was 44.6 years for the corticotrophin group and 43.9 years for the prednisolone group.

Assessment of the result of treatment is a difficult problem even if very elaborate methods are used. The presence or absence of denervation can be determined by the appearance of associated movements (Langworth and Taverner, 1963), and this is the strictest criterion available. The results now reported are based almost entirely on this finding. We are well aware of the unreliability of subjective estimates of the difference in movement of the two sides of the face, but the statistically significant differences reported here are considerable and it is unlikely that observer error is responsible. The actual assessments of recovery in the severely denervated patients receiving corticotrophin mentioned above were $10 \%, 15 \%, 10 \%, 10 \%$, $15 \%$, and $15 \%$, while all who took prednisolone were assessed at $50 \%$ recovery or above.

We had hoped to show that corticotrophin injections gave better results than oral prednisolone if only because a previous trial of cortisone for Bell's palsy gave a negative result (Taverner, 1954). In retrospect it is clear that the 1954 trial was inadequately planned to produce a reliable result. The treatment was started far too late to be effective, the dose of cortisone was too low, and the number of patients tested was too small.

At present we believe that oral prednisolone is the treatment of choice in Bell's palsy and should be given in full doses from the day of onset. The small risk of serious side effects is acceptable in view of the significant reduction in the incidence of severe denervation.

\section{References}

Jönsson, B., Reis, G. von, and Sahlgren, E. (1951). Acta Psychiatrica et Neurologica, Suppl. No. 74, p. 60 .

Langworth, E. P., and Taverner, D. (1963). Brain, 86, 465.

Miller, H., Newell, D. J., and Ridley, A. (1961). Lancet, 2, 1120

Peiris, O. A., and Miles, D. W. (1965). British Medical fournal, 2, 1162.

Ross, J., Colmant, H. J., and Böhm, P. (1958). Deutsche Zeitschrift für Nervenheilkunde, $177,475$.

Taverner,D. (1954), Lancet, 2, 1052.

Taverner, D., Fearnley, M. E., Kemble, F., Miles, D. W., and Peiris, O. A. (1966). British Medical fournal, 1, 391.

\title{
Thiopropazate Hydrochloride in Persistent Dyskinesia
}

\author{
K. SINGER, M. N. CHENG
}

British Medical fournal, 1971, 4, 22-25

\section{Summary}

Thiopropazate (Dartalan) was found to be significantly more effective than a placebo in relieving dyskinesia in 23 patients with functional psychosis and persistent dyskinesia associated with prolonged phenothiazine therapy. Each patient whose dyskinesia had persisted unchanged for at least one month after phenothiazine withdrawal received thiopropazate by mouth for three weeks and the placebo for a similar period. Patients were evaluated before the trial, at three weeks, and at six weeks.

The drug also improved psychotic behaviour. Possible side effects, which were generally mild, were noted in eight patients, of whom six had Parkinsonism and four drowsiness. None had side effects while on the placebo.

The findings indicate that thiopropazate is of value in persistent dyskinesia associated with prolonged phenothiazine intake-a condition hitherto unresponsive to

\section{University of Hong Kong, Hong Kong}

K. SINGER, M.R.C.P.ED., D.P.M., Lecturer in Psychiatry and Specialist in Charge, Mental Health Service

Castle Peak Hospital, Hong Kong

M. N. CHENG, M.B., B.S., Medical Officer other treatment. Further research is required to determine the long-term effectiveness of the drug.

\section{Introduction}

The treatment of persistent dyskinesia associated with prolonged phenothiazine therapy has been unsatisfactory. Brandrup (1961) reported success with tetrabenazine in four patients (but we could find no further report on the value of this drug) and Roxburgh (1970) used thiopropazate successfully in two patients.

Thiopropazate hydrochloride (Dartalan) is chemically described as 10-(3[4-(2-acetyoxyethyl)piperazin-1-yl]propyl)-2chlorophenothiazine dihydrochloride and is a phenothiazine structurally closely related to chlorpromazine. It has been reported to be of value in schizophrenia (Hamilton et al., 1960). Reports on its effectiveness in controlling choreiform movements have been confined to Huntingdon's chorea (Mathews, 1958; Bruyn, 1962; Lyon, 1962) apart from, so far as we can trace, one case each of non-hereditary chorea (Lyon, 1962), probable senile chorea with polycythaemia (Heathfield, 1968), and Sydenham's chorea activated by oral contraceptives (Lewis and Harrison, 1969). Kabat and McLeod (1959) reported improvement of involuntary movements in 24 cases of cerebellar ataxia and intention tremor.

Persistent dyskinesia affecting the face, mouth, tongue, and jaw (oral dyskinesia) is well known as an insidious and late 
development of protracted phenothiazine intake. The syndrome has been reviewed by Crane (1968) and Kline (1968) and its relation to other phenothiazine-induced dysfunctions discussed by Faurbye (1970). Some of the patients also showed dyskinesia affecting the neck, limbs, and trunk, manifesting usually as generalized restlessness or minor choreiform movements at the extremities (Faurbye et al., 1964; Hunter et al., 1964; Pryce and Edwards, 1966). More violent generalized choreiform movements may also occur (Druckman et al., 1962; Roxburgh, 1970; Singer and Wong, 1970).

While there is general agreement that the above syndrome exists, there is divergence of opinion on its frequency, aetiology, and clinical characteristics. The relation between dyskinesia and phenothiazines has not been finally established but the evidence strongly suggests it exists. Apart from the known effect of phenothiazines on the extrapyramidal system, the dosage of phenothiazine seems to have a direct bearing on the development of dyskinesia (Pryce and Edwards, 1966). Kline (1968) argued that most of the reported cases are accountable for by concomitant or pre-existing organic lesions. Certainly there are indications that organic and constitutional factors and old age predispose to the development of the syndrome (Brandon et al., 1971), but many cases show no evidence of brain damage and have a history only of prolonged phenothiazine intake. In the present state of knowledge it seems that prolonged intake of phenothiazine is one of a number of possible aetiological factors.

We report here a clinical evaluation of thiopropazate hydrochloride in the treatment of persistent dyskinesia associated with prolonged phenothiazine therapy.

\section{Patients and Methods}

The trial was double-blind with a cross-over design. Each patient was allotted a serial number and randomly allocated to one of two groups (A and B) by an independent colleague whose only knowledge of the patients was a list of their names. The code was given to the pharmacist with instructions to treat the two groups according to the following schedule:

\begin{tabular}{|c|c|c|c|}
\hline & & First 3-week Period & Second 3-week Period \\
\hline $\begin{array}{l}\text { Group A } \\
\text { Group B }\end{array}$ & .. & $\begin{array}{ll}\text {.. Thiopropazate } & \text { Th } \\
. & \text { Placebo }\end{array}$ & $\begin{array}{ll}\ldots & \text { Placebo } \\
\ldots & \text { Thiopropazate }\end{array}$ \\
\hline
\end{tabular}

Thiopropazate $10 \mathrm{mg}$ and placebo tablets identical in appearance and taste were made up in individual bottles each containing three weeks' supply. The bottles were serially numbered by the pharmacist who kept the code. They were labelled only with the patient's name, bottle serial number, instructions to take one-and-a-half tablets three times a day after meals, and the date and time of the first dose. The first batch of bottles was delivered to the nursing staff the day before the trial, the second batch at three weeks. The nursing staff were instructed to ensure that they saw the patients swallow the drugs and to report irregularities.

All patients were put in one ward for each sex. All drugs were withdrawn for the duration of the trial except for nonneuroleptic sedatives in emergencies. Otherwise no change was made in the patients' routine. Side effects were noted only if the patient spoke of them or the investigators and nursing staff observed them. Treatment for Parkinsonism was to be given when necessary.

All the patients in the trial were inpatients (22 Chinese, 1 Eurasian) of both sexes in Castle Peak Hospital which has 1,700 patients and is the only psychiatric hospital for the whole of Hong Kong's four miliion population. All patients in the hospital were screened for cases of persistent dyskinesia and 23 were found that fulfilled the following criteria: (1) they had dyskinesia (see below for definition); (2) the dyskinesia had persisted unchanged for at least one month after phenothiazine withdrawal; (3) onset of dyskinesia was at least one year after the start of phenothiazine treatment; (4) the original diagnosis was a functional psychosis; and (5) there was no organic disorder present known to cause involuntary movements, such as Huntington's chorea, senile and other choreas and athetoses, presenile and senile dementia, or a family history of involuntary movements or dementia. While every effort was made to obtain a homogenous group, and particularly to exclude cases with an organic "flavour," it was impracticable to exclude those who had had electric convulsion therapy (all patients) and leucotomy (two patients).

\section{DEFINITION OF DYSKINESIA}

By dyskinesia was meant involuntary, stereotyped, and rhythmic movements which included choreiform, choreo-athetotic, and athetotic movements, as follows. (1), Oral dyskinesia, in which one or more of the following regions were involved: tongue (as exemplified by forwards and backwards, side-to-side, torsion, and rotatory movements), lips (pursing, sucking, twisting, and opening and closing movements), face (grimacing movements), jaw (chewing and munching movements), and throat (dysarthria and swallowing difficulties). (2) Bodily dyskinesia, in which one or more of the following regions were involved: neck (spasmodic, writhing, nodding, torticollic, or retrocollic movements), limbs (choreic, athetotic, and choreoathetotic movements), trunk (spasmodic, writhing, and rotatory movements and respiratory irregularities).

Care was taken to exclude functional habit spasms and the mannerisms of psychotics. One-sixth of the patients selected also had mild to moderate Parkinsonism (rigidity).

\section{ASSESSMENT}

Patients were evaluated the day before the trial and at three and six weeks. Complete psychiatric and physical examinations were carried out on each occasion and reporting forms completed. Patients were also seen at weekly intervals at least and separate entries were made in their case notes. Dyskinesia was rated according to rating scales constructed to quantify the observations for statistical analysis. Three rating scales were devized to cover possibly different though overlapping aspects of the dyskinesia.

Global.-The rating was by general overall impression of the intensity and extent of dyskinesia. Scoring was from 0 for absent to 4 for severe dyskinesia (violent, ceaseless movements involving at least the whole of one region-face, neck, trunk, limbs).

Multidimensional.-A five-point scale as for the global was used for each of four bodily regions (face, neck, trunk, and limbs) and the scores were totalled (maximum total score $=16$ ).

Facial movements. - The number of involuntary movements of the face or lips whenever they were faster was counted. Absence of movements was given a score of $0 ; 1-15$ movements/ minute, 1 ; 16-30 movements/minute, 2 ; 31-45 movements/ minute, 3 ; and 46 or more movements/minute, 4 .

Interobserver test reliability was estimated by a comparison of the ratings in 17 patients using all three scales and carried out by one of us (C.M.N.) and an independent colleague. The coefficient of correlation of the ratings was 0.96 for the global, 0.87 for the multidimensional, and 0.82 for the facial scales.

Changes in the patients' psychiatric condition were also evaluated by comparing the condition the day before the trial with that at three and at six weeks. Changes were rated on a seven-point scale ranging from a score of -3 for much worse through 0 for no change to 3 for marked improvement. All the ratings were carried out by C.M.N. with the patients sitting unoccupied. 


\section{STATISTICAL METHODS}

Significance of differences related to effect of clinical variables on response was determined by the $\chi^{2}$ test (incorporating correction for continuity), and those related to a comparison of clinical characteristics which involve proportions in groups $\mathrm{A}$ and $B$ by the standard test based on normal distribution. Significance of differences in placebo groups A and B was determined by the standard $t$ test, fractional improvement scores being used to eliminate possible differences between their pretrial scores. All other probabilities reported were based on Student's $t$ test for paired observations. It was realized at the outset that the tests based on Student's $t$ and normal distribution were valid only for normally and independently distributed normal variates. This fact was borne in mind in the construction of the three rating scales and the scoring system. The $t$ test was also preferred to the nonparametric Wilcoxon's signed ranks test, since the proportion of tied ranks in the data was relatively high.

\section{Results}

All 23 patients selected completed the six weeks' trial. On breaking the code it was found that 12 belonged to group A and 11 to group B. The dosage did not have to be varied because of side effects or for other reasons.

The mean age of the patients was $52 \cdot 1$ years (S.D. 13.1); nine were males and 14 females; and 21 were schizophrenic and two affective. The mean length of psychotic illness (including periods of remission) was $11 \cdot 3$ years (S.D. 7.0), of dyskinesia $22 \cdot 1$ months (S.D. 33.2), of phenothiazine treatment $8 \cdot 2$ years (S.D. 4.2), and of dyskinesia after phenothiazine withdrawal $6 \cdot 2$ months (S.D. $7 \cdot 1$ ). Eleven had only facial involvement and the remainder had also bodily involvement. Groups A and B were found not to differ significantly except for distribution of dyskinesia.

It will be seen (Table I) that thiopropazate more effectively relieved dyskinesia than placebo. The difference is statistically significant in all three rating scales. Also on thiopropazate 18 were improved, three unchanged, and two worse.

TABLE I-Effect of Thiopropazate and Placebo on Dyskinesia: Comparison of Improvement Scores

\begin{tabular}{|c|c|c|c|c|c|c|}
\hline \multirow[t]{2}{*}{ Scale } & \multicolumn{2}{|c|}{$\begin{array}{c}\text { Thiopropazate } \\
\mathrm{n}=23\end{array}$} & \multicolumn{2}{|c|}{$\begin{array}{l}\text { Placebo } \\
\mathbf{n}=23\end{array}$} & \multirow[t]{2}{*}{$t^{*}$} & \multirow[t]{2}{*}{$\mathbf{P}$} \\
\hline & Mean & S.D. & Mean & S.D. & & \\
\hline $\begin{array}{l}\text { Global . . } \\
\text { Multidimensional } \\
\text { Facial }\end{array}$ & $\begin{array}{l}2 \cdot 13 \\
3 \cdot 57 \\
2 \cdot 04\end{array}$ & $\begin{array}{l}1.98 \\
5.05 \\
2.12\end{array}$ & $\begin{array}{l}0.52 \\
1.30 \\
0.22\end{array}$ & $\begin{array}{l}0.82 \\
2 \cdot 12 \\
1.38\end{array}$ & $\begin{array}{l}5 \cdot 0 \\
2 \cdot 2 \\
4 \cdot 0\end{array}$ & $\begin{array}{l}<0.0005 \\
<0.05 \\
<0.0005\end{array}$ \\
\hline
\end{tabular}

* Matched pair, one-tailed test.

To see if patients on placebo changed from their pretrial condition their pretrial and postrial scores were compared. Those on placebo were found to have improved significantly in the global and multidimensional scales but not in the facial scale. The placebo effect was also compared in group A and B patients. Those in group $A$ had received thiopropazate before the placebo and in group $B$ after the placebo. Fractional improvement scores were utilized, because comparison was being made between two dissimilar groups. The differences were not significant in any of the three scales. This indicates that in spite of there being no time gap between the drug and the placebo periods there was no carry-over effect of thiopropazate in group $B$ as assessed at the end of the trial period.

Age, sex, severity of dyskinesia, total duration of dyskinesia, duration of dyskinesia after phenothiazine withdrawal, lateness of onset of dyskinesia, duration of phenothiazine treatment and of withdrawal, length of psychotic illness, or distribution of dyskinesia did not influence the response to thiopropazate (or to placebo) according to all three rating scales.*

Possible side effects were noted in eight patients receiving thiopropazate-six had Parkinsonism, mainly in the form of rigidity, and four drowsiness. Four patients had had Parkinsonian rigidity before the trial so that some of this seen during the trial was probably not attributable to the drug. None had side effects while on placebo. The Parkinsonism was severe in only one patient, in whom it was relieved by benzhexol.

Thiopropazate and placebo scores with the psychiatric rating scale were compared. Thiopropazate was significantly better than placebo in improving psychotic behaviour (Table II).

TABLE II-Effect of Thiopropazate and Placebo on Psychiatric Condition: Comparison of Thiopropazate and Placebo scores on Psychotic Behaviour Rating Scale

\begin{tabular}{c|c|c|c|c|c}
\hline \multicolumn{2}{c|}{$\begin{array}{c}\text { Thiopropazate } \\
\mathrm{n}=23\end{array}$} & \multicolumn{2}{c|}{$\begin{array}{c}\text { Placebo } \\
\mathrm{n}=23\end{array}$} & \multirow{2}{*}{$t^{*}$} & $\mathrm{P}$ \\
\hline Mean & S.D. & Mean & S.D. & & \\
\hline 0.914 & 0.79 & 0.174 & 0.78 & 3.02 & $<0.005$ \\
\hline
\end{tabular}

*Matched-pair, one-tailed test.

\section{Discussion}

Most of the patients were improved on thiopropazate, some dramatically so. This was particularly evident in the severer cases. The pretrial scores of the four severest of $16,16,14$, and 10 on the multidimensional scale compare with postrial scores of $16,0,0$, and 0 respectively - that is, no change in one and complete remission in the others. However, one of the other cases was markedly worse on thiopropazate and completely relieved by placebo. Benefit was evident within two to three days. The effect was symptomatic, a complete relapse occurring within three to four days of withdrawal at the end of the trial. Improvement was maintained throughout the period of trial and tolerance did not develop. Speech, when affected, became coherent, and owing to the reduction of involuntary movements motor function was restored. Psychotic behaviour also improved and the patients became more easily manageable.

It is noteworthy that the supposedly distinctive features of persistent or tardive dyskinesia-total duration of dyskinesia, duration of dyskinesia after phenothiazine withdrawal, lateness of onset, and oral involvement-had no correlation with response to thiopropazate. This suggests that these features do not characterize and demarcate the syndrome from dyskinesia of short duration, early onset, and affecting other bodily regions induced by phenothiazines. It is also interesting that the severity of dyskinesia, which implies the extent of the damage induced by phenothiazines, had no bearing on response.

It is reasonable to assume that thiopropazate was responsible for some of the Parkinsonism seen during the trial since, though one-sixth of the patients had Parkinsonism before, one-quarter had it during the trial. Also the drug is known to cause Parkinsonism. The therapeutic benefit was to an extent vitiated by this side effect, which can be ameliorated by a reduction in dosage. Experience from the trial showed that $15 \mathrm{mg}$ three times a day was too high an average dose.

The mode of action of thiopropazate in improving involuntary movements is unknown. It seems paradoxical that thiopropazate, a phenothiazine, should be effective in a syndrome probably induced by other phenothiazines. However, thiopropazate has been reported to be effective in the superficially similar syndrome of Huntington's chorea and was on this basis first used to treat oral dyskinesia (Roxburgh, 1970). Another example of an apparently paradoxical effect is the exacerbation of phenothiazine-induced dyskinesia after phenothiazine withdrawal

* Statistical details for these and other comparisons may be obtained from the authors. 
(Kennedy, 1969). Also reminiscent of this sort of effect is the Parkinsonism associated with the phenothiazines used in psychiatry compared with the opposite effect of the anticholinergic phenothiazines-for example, diethazine.

In conclusion, thiopropazate seems to be an effective drug in the short term for persistent dyskinesia. This finding, if confirmed, is clinically useful in view of the increasing frequency with which the condition is being reported and its lack of response to other treatment. Whether thiopropazate can be recommended as the phenothiazine of choice in those predisposed to dyskinesia, such as the elderly and brain-damaged, cannot be decided at this stage, since its antipsychotic value relative to that of other phenothiazines has to be considered. Further research on its long-term effectiveness is needed.

We are indebted to the Director of Medical and Health Services for permission to publish, to Mrs. M. N. Cheng for help with statistical work, and to Dr. W. Inglis, of Messrs. G. D. Searle, Sydney, for providing the Dartalan and placebo tablets.

\section{References}

Brandon, S., McClelland, H. A., and Protheroe, C. (1971). British Fournal of Psychiatry, 118, 171.

Brandrup, E. (1961). American fournal of Psychiatry, 118, 551.

Bruyn, G. W. (1962). Psychiatria, neurologia, neurochirurgia, 65, 430.

Crane, G. E. (1968). American fournal of Psychiatry, 124, Feb. Suppl., p. 40.

Druckman, R., Seelinger, D., and Thulin, B. (1962). Fournal of Nervous and Mental Disease, 135, 69.

Faurbye, A. (1970). Comprehensive Psychiatry, 2, 205.

Faurbye, A., Rasch, P. J., Petersen, P B., Brandborg, G., and Pakkenberg, H. (1964). Acta psychiatrica et neurologica Scandinavica, 40, 10.

Hamilton, M., Smith, A. L. G., Lapidus, H. E., and Cadogen, E. P. (1960). Fournal of Mental Science, 106, 40.

Heathfield, K. W. G. (1968). British Medical fournal, 1, 250

Hunter, R., Earl, G. J., and Thornicroft, S. (1964). Proceedings of the Royal Society of Medicine, 57, 758.
S.

Kabat, H., and McLeod, M., (1959). Connecticut State Medical fournal, 23, 710.

Kennedy, P. F. (1969). British fournal of Psychiatry, 115, 103.

Kline, N. S. (1968). American fournal of Psychiatry, 124, Feb. Suppl., p. 48. Lewis, P. D., and Harrison, M. J. G. (1969). British Medical fournal, 4, 404. Lyon, R. L. (1962). British Medical fournal, 1, 1308.

Mathews, F. P. (1958). American fournal of Psychiatry, 114, 1034.

Pryce, I. G., and Edwards, H. (1966). British fournal of Psychiatry, 112, 983.

Roxburgh, P. A. (1970). British fournal of Psychiatry, 116, 277.

Singer, K., and Wong, M. (1970). Postgraduate Medical fournal, 46, 634.

\section{PRELIMINARY COMMUNICATIONS}

\section{Persistent Phenothiazine Dyskinesia Treated with Tetrabenazine}

\author{
R. B. GODWIN-AUSTEN, T. CLARK
}

British Medical fournal, 1971, 4, 25-26

\section{Summary}

Six patients with persistent phenothiazine dyskinesia were treated in a double-blind controlled trial with tetrabenazine $100 \mathrm{mg}$ in divided dosage. In three patients the abnormal movements were abolished and in two others there was some improvement, but this was no greater than that achieved with the diazepam control. Tetrabenazine may be useful in the treatment of some patients with persistent phenothiazine dyskinesia.

\section{Introduction}

The persistent facial dyskinesia which sometimes occurs after treatment with phenothiazines is similar to the abnormal movements of the face and tongue seen as a complication of levodopa treatment of Parkinson's disease (Sigwald, Bouttier, Raymondeaud, and Piot, 1959; Hunter, Earl. and Thorneycroft, 1964). To see whether persistent phenothiazine dyskinesia would benefit from drugs which interfere with normal dopamine metabolism we treated a small group of patients with tetrabenazine. This drug, like reserpine, produces a depletion of dopamine and serotonin in the brain (Pletscher, Brossi, and Grey, 1962) and might therefore be expected to benefit dyskinesia if abnormal movements result from excessive sensitivity to normal brain dopamine release or excessive endogenous dopamine formation.

The National Hospital, Queen Square, London W.C.1

R. B. GODWIN-AUSTEN, M.D., M.R.C.P., Senior Registrar. (At present, Consultant Neurologist, General Hospital, Nottingham NG1 6HA)

Friern Hospital, New Southgate, London N.11

T. CLARK, M.R.C.S., D.P.M., Registrar, Department of Psychiatry

\section{Patients and Methods}

Six women long-stay inpatients of a psychiatric hospital aged 70 to 85 were investigated. They were moderately or severely demented. Two had had a leucotomy, three had had electric convulsion therapy, and all had been taking a phenothiazine for more than a year. The phenothiazines were chlorpromazine in doses up to $300 \mathrm{mg}$ daily and trifluoperazine up to $15 \mathrm{mg}$ three times a day, with or without anti-Parkinsonian agents. All had developed facial movements which had persisted for periods of from 6 to 12 years. Three of the patients were included in a series described by Hunter et al. (1964).

The response of the patients was recorded with a double-blind method, and three courses of treatment were given to each subject. The courses were in random sequence and consisted of one week's treatment each with placebo, diazepam, and tetrabenazine. Identical tablets were used containing either placebo, diazepam $1 \mathrm{mg}$, or tetrabenazine $25 \mathrm{mg}$. One tablet was given twice daily for three days and then four times daily for four days. Assessment was carried out on different days by two doctors who did not know the drug regimen. Cine films were taken of each patient on the last day of each trial period. The sequence of the films were later randomized and scored by Dr. D. Marsden, who had no knowledge of the patients. There were thus three independent assessments of the responses of these patients to treatment. Scoring was on a simple fourpoint scale.

\section{Results}

The results are shown in the Table. In three cases abnormal movements were absent during the period of treatment with tetrabenazine. In two others there was a mild reduction of abnormal movements but their response at this dosage of

Scores before and after Treatment

\begin{tabular}{|c|c|c|c|c|}
\hline \multirow{2}{*}{$\begin{array}{l}\text { Case } \\
\text { No. }\end{array}$} & \multirow{2}{*}{$\begin{array}{c}\text { Before } \\
\text { Treatment }\end{array}$} & \multicolumn{3}{|c|}{ Treatment } \\
\hline & & Placebo & Diazepam & Tetrabenazine \\
\hline $\begin{array}{lll}1 & \cdots & \\
2 & \cdots & \\
3 & \cdots & \\
4 & \cdots & \\
5 & \cdots & \\
6 & \cdots & \\
6\end{array}$ & $\begin{array}{l}9 \\
8 \\
4 \\
6 \\
4 \\
7.5\end{array}$ & $\begin{array}{l}8.5 \\
6 \\
5 \\
6 \\
4 \\
6\end{array}$ & $\begin{array}{l}8 \\
4.5 \\
3 \\
3.5 \\
2.5 \\
4.5\end{array}$ & $\begin{array}{l}7 \\
4 \\
0 \\
0 \\
0 \\
6\end{array}$ \\
\hline
\end{tabular}

